www.jmscr.igmpublication.org

Impact Factor (SJIF): 6.379

Index Copernicus Value: 71.58

ISSN (e)-2347-176x ISSN (p) 2455-0450

crossref DOI: _https://dx.doi.org/10.18535/jmscr/v6i4.117

Journal Of Medical Science And Clinical Research

$\underline{\text { Research Article }}$

\title{
Comparative Study of Lipoprotein (A) Level in Patients of Acute Coronary Syndrome with Type II Diabetes and Non Diabetics in a Tertiary Care Hospital of Central India
}

\author{
Authors \\ Dr Amita Gupta ${ }^{1}$, Dr Rajeev Lohokare ${ }^{2}$, Dr Purnima Dey Sarkar ${ }^{3}$ \\ Department of Biochemistry, Mahatma Gandhi Memorial Medical College, Indore, M.P., 452001 \\ Corresponding Author \\ Dr Amita Gupta \\ Address: 6, Nandgoan, Nandvihar, Near Girdhar nagar, Indore, M.P., 452001 \\ Mobile No.8109145378, 8223068877, Email: amita.guptagmc@gmail.com
}

\begin{abstract}
Objective: To compare the lipoprotein (a) level in type II diabetics and non diabetics with acute coronary syndrome.

Materials and Methods: A total of 80 subjects including 40 patients with type II diabetes as cases and 40 non diabetics as control admitted in ICU matched for age and sex included in the study. Serum FBS, TG, cholesterol, LDL, HDL and serum Lp (a) in both the groups were measured. Statistical analysis was performed using SPSS software.

Results: Lp (a) level was significantly higher $(p<0.001)$ in diabetics as compared to control group.

Conclusion: Study concluded that increased serum $L p(a)$ concentration might be a risk factor in type II diabetic patients for coronary artery disease.

Keywords: Lipoprotein (a),type II diabetes, Acute coronary syndrome.
\end{abstract}

\section{Introduction}

Among the most common chronic disorders of modern times, diabetes mellitus $(\mathrm{dm})$ remains unique because of its multisystem ramifications. Multiple factors like hypertension, dyslipidemia, insulin resistance, hyperinsulinemia, glucose intolerance and obesity, particularly central obesity, has been termed "metabolic syndrome" ${ }^{\text {(1,2) }}$, which is a powerful determinant of type II DM and cardiovascular disease ${ }^{(3)}$.

Coronary artery disease (CAD) has a multi factorial origin, including hereditary and acquired risk factors which may be the direct cause of the disease or merely associated with it. Changes in lipid metabolism play a relevant role in the progression of atherosclerosis and the laboratory assessment of lipoproteins is of fundamental importance to diagnose and

treat this condition. $\mathrm{Lp}(\mathrm{a})$ has been reported to be an independent risk factor for premature CAD and other thromboembolic disorders ${ }^{(4-7)}$. The present study was undertaken to find out the association of $\mathrm{Lp}$ (a) with acute coronary syndrome found in type 2 diabetic patients. 


\section{Methodology}

For the present cross-sectional study, Fourty Type 2 diabetic patients and fourty non diabetic patients admitted with acute coronary syndrome were selected after matching for age and sex, during the study period. Patients with angina, occurring at rest (CCS class IV) of duration more than 30 minutes, but within 24 hours from onset of angina were included in the study. Diabetes was ruled out in non diabetic group with fasting and 2-hr post prandial blood glucose measurement. Patients presenting $24 \mathrm{hrs}$ after occurrence of angina, angina secondary to extra cardiac causes. (eg. Anaemia, thyrotoxicosis), Patients who were currently on drugs which may alter serum levels of Lp (a) eg. Oral contraceptive pills, cholesterol lowering agents, aspirin, hormone replacement therapy, antiepileptics $)^{(8-10)}$, Prediabetic patients were excluded from both groups. ${ }^{(1)}$, All type of renal failure patients including diabetic nephropathy ${ }^{(12)}$ were excluded from the study.

Lipoprotein (a) level was studied in these patients. The study protocol was approved by the institutional ethical committee and an informed consent was taken by all the subjects.

\section{Collection of Data \& Analytical Methods}

In the present study eighty acute coronary syndrome patients, who were divided in to two separate age and sex matched groups; one with type 2 diabetes mellitus and one without Diabetes mellitus, were selected during the study period as per the inclusion and exclusion criteria. A detailed history (with emphasis on angina/angina like symptoms) was taken and a detailed physical examination was done as per the proforma .Blood sample was taken. All diabetics are of type II diabetes mellitus, currently on oral hypoglycemic agents. In non diabetic group diabetes mellitus was ruled out by fasting and post prandial blood glucose. In all 80 patients serum Lp(a) level and lipid profile was estimated. Serum was analyzed in automated analyzer for total cholesterol (TC enzymatic CHOD-PAP), triglycerides (TG enzymatic GPO-PAP), HDL-C (precipitation method) and fasting blood sugar (FBS enzymatic (GOD-POD). LDL-c was calculated by Friedewald formula. Lipoprotein (a) analyzed by automated analyzer whose kit was based on principle of turbidimetry.

\section{Statistical Analysis}

Data was maintained on excel spread sheet. Analysis was performed using SPSS software. Descriptive data were expressed as mean, standard deviation, and range of all variables. Results were presented as mean \pm S.D. Means of data in patients and controls were compared using the independent $\mathrm{t}$-test. Differences were considered statistically significant at $\mathrm{p}<0.05 \&$ highly significant at $\mathrm{p}<0.001$.

\section{Results}

Out of 40 patients of type II diabetes mellitus, there were 12 females and 28 male and among 40 non diabetic controls 16 were female \& 24 were male. The difference in Lipoprotein(a) levels between cases and control were statistically highly significant. Triglycerides shows a significant increased level as compared to control. Difference in HDL-C between the two groups was non significant.

Table 1: Gender based Distribution of the

Subjects

\begin{tabular}{|l|c|c|}
\hline Sex & Control $(\mathbf{N}=\mathbf{4 0})$ & Case(N=40) \\
\hline Male & $24(60 \%)$ & $28(70 \%)$ \\
\hline Female & $16(40) \%$ & $12(30 \%)$ \\
\hline Total & $40(100 \%)$ & $40(100 \%)$ \\
\hline
\end{tabular}

This table shows that out of 40 control $60 \%$ were males and $40 \%$ were females whereas in cases $30 \%$ were females and $70 \%$ were males.

Table 2: Comparison of biochemical parameters between Control and Diabetic Patients

\begin{tabular}{|c|c|c|c|}
\hline $\begin{array}{l}\text { Parameters } \\
(\mathbf{m g} / \mathbf{d l})\end{array}$ & $\begin{array}{c}\text { Controls } \\
(\mathrm{N}=40) \\
(\mathrm{Mean} \pm \text { S.D })\end{array}$ & $\begin{array}{l}\text { Cases }(\mathrm{N}=40) \\
(\text { Mean } \pm \text { S.D })\end{array}$ & $\begin{array}{c}\text { P- } \\
\text { Value* }\end{array}$ \\
\hline Total Cholesterol & $167.8 \pm 31.89$ & $192.1 \pm 42.67$ & $<0.001$ \\
\hline Triglycerides & $145.85 \pm 51.90$ & $168.97 \pm 72.26$ & $<0.05$ \\
\hline LDL-C & $92.21 \pm 27.16$ & $111.26 \pm 36.60$ & $<0.001$ \\
\hline HDL-C & $32.06 \pm 6.83$ & $29.58 \pm 8.30$ & $>0.05$ \\
\hline Lipoprotein (a) & $18.33 \pm 11.09$ & $26.01 \pm 12.45$ & $<0.001$ \\
\hline
\end{tabular}

Above table shows comparison of biochemical parameters between control and cases of type II 
diabetes, it shows highly significant increased level of lipoprotein (a), total cholesterol and LDL$\mathrm{C}$ as compared to control. Triglycerides shows a significant increased level as compared to control. Difference in HDL-C between the two groups is non significant.

\section{Discussion}

Different factors have been found to be responsible for an increased prevalence of CAD in DM. One of these are the elevated levels of serum $\mathrm{Lp}(\mathrm{a})^{(13)}$.Our study has revealed that $\mathrm{Lp}(\mathrm{a})$ levels were significantly elevated in type II dm patients. In diabetes mellitus, $67 \%$ of deaths are due to coronary artery disease. Framingham heart study showed that $\mathrm{CAD}$, acute myocardial infarction and sudden death is 1-5 fold increased in diabetes patients $^{(14)}$. The ratio between male and female patients in both controls and cases were proportionate in all the studies. Gender bias is also removed as both the groups are matched.

In the present study, $\mathrm{Lp}$ (a) values varied from 5 to $57 \mathrm{mg} / \mathrm{dl}$. Type- 2 diabetic patients had higher Lp(a)level as compared to non diabetic patients. The difference of means was statistically highly significant $(p<0.001)$. This was comparable with Mohan et al, Neki et al, and Salehi et al ${ }^{(14-16)}$. In the present study, considering the optimal cut off points at $15 \mathrm{mg} / \mathrm{dl}, 76 \%$ of type- 2 diabetic patients had Lp (a) $>15 \mathrm{mg} / \mathrm{dl}$, compared to $21 \%$ of non diabetic patients.

Various studies state that there is no increase of Lp(a)concentration in patients with type II DM. However in the present study we found that LP( a) levels were increased in type II DM patients which is in agreement with the studies of Ramirez LC etal. ${ }^{(17)}$. Serum levels of $\mathrm{Lp}(\mathrm{a})$ have been shown to correlate with presence, extent and severity of coronary artery disease. PROCAM studies shows that high level of $\operatorname{lp}(\mathrm{a})$ is an independent risk for CAD.

In the later stages of type $2 \mathrm{DM}$, insulin secretion declines, with progressive loss of beta cells as well as worsening of the glycemic control. The risk of cardiovascular mortality and morbidity also increases with longer duration of DM ${ }^{(18)}$.

The concentration of glycosylated $\mathrm{Lp}(\mathrm{a})$ is increased in the circulation of diabetic subjects. It is evident that glycosylation prolongs the half-life of lipoproteins and likewise for $\operatorname{Lp}(\mathrm{a})$. This can lead to elevated levels of $L p(a)$ in diabetic individuals(19).Patients with type 2 diabetes and insulin resistance are at a markedly increased risk of atherosclerosis, and because strict control of glycemia has proved beneficial in reducing microangiopathy but not macroangiopathy, the treatment of diabetic dyslipidemia should be aggressive.

Microalbuminuria is known to be a predictor of increased risk of cardiovascular disease and early mortality in diabetes. Also $L p(a)$ levels are elevated in patients with microalbuminuria, and $\mathrm{Lp}(\mathrm{a})$ is a known risk factor for cardiovascular disease. Thus, elevated $L p(a)$ may be one of the factors responsible for increased incidence of cardiovascular disease in diabetic patients with microalbuminuria.

One of the risk factors in long standing DM may be increasing $\mathrm{Lp}(\mathrm{a})$ levels. The association of $\mathrm{Lp}$ (a) levels in DM has been a matter of some controversies. The major reasons for the discrepant results of the prospective studies have been attributed to the variation in study design, collection and storage of samples, methods used for statistical analysis and population differences that reflect the known ethnic variability in the distribution of $\mathrm{Lp}(\mathrm{a})$ levels and Apo(a) size isoforms $^{(20)}$.

\section{Conclusion}

Type-2 diabetic patients have higher level of Lp(a) during acute coronary syndrome when compared to non diabetic group. Elevated Lp(a) in type -2 diabetic patients contribute to the accelerated atherogenic state,causing major adverse cardiac events.

Study concluded that increased serum $\mathrm{Lp}(\mathrm{a})$ concentration might be a risk factor in type II diabetic patients for coronary artery disease. The 
possible pathogenetic role of $\operatorname{lp}(\mathrm{a})$ in diabetes and the cardiac events deserves to be further studied.

No grants was sectioned for the project.

\section{References}

1. Reaven GM. Role of insulin resistance in human disease. Diabetes. 1988; 37: 1595-607.

2. De Fronzo RA, Ferrannini E. Insulin resistance: a multifaceted syndrome responsible for NIDDM, obesity, hypertension, dyslipidemia, and atherosclerotic cardiovascular disease. Diabetes Care. 1991; 14: 173-94.

3. Ferrannini E, Haffner SM, Mitchell BD, Stern MP. Hyperinsulinaemia: the key feature of a cardiovascular and metabolic syndrome. Diabetologia. 1991; 34: 416-22.

4. Morton NE, Berg-K, Dahlen G, Ferrell RE, Rhoads GG. Genetics of the Lp(a) lipoprotein in Japanese-Americans. Genet Epidemiol 1985;2: 113-2 1 .

5. Berg K, Dahlen G, Frick MH. Lp(a) lipoprotein and pre-i11-lipoprotein in patients with coronary heart disease. Clin Genet 1974;6:230-5.

6. Rhoads GG, Dahlen G, Berg K, Morton NE, Dannenberg AL. Lp(a) lipoprotein as a risk factor for myocardial infarction. JAMA 1986;256: 2540-4.

7. Rosengren A, Wilhelmsen L, Eriksson E, Risberg B, Wedel H. Lipoprstcin (a) and coronary heart disease: a prospective casecontrol study in a general population sample of middle aged men. BM7 1990;301:1248-51.

8. Utermann G: The mysteries of lipoprotein(a). Science 1989; 246:904-910.

9. Kronenberg F, Steinmetz A, kostner GM and Dieplinger $\mathrm{H}$ : Lipoprotein in health and disease. Crit Rev Clin Lab Sci 1996; 33:495543.

10. Gurakar A, Hoeg JM, Kostner G et al. Levels of lipoprotein $\mathrm{Lp}(\mathrm{a})$ decline with neomycin and niacin treatment. Atherosclerosis. 1985; 57:293-301.

11. World Health Organisation: Diabetes Mellitus: Report of a WHO study group. Geneva, World Health Org,.1996(Tech Reo Ser No. 855).

12. Bostem AG, Cupples LA, Srivastava LM. Lipoprotein (a): Biology and role in atherosclerotic vascular disease. Current Science 1999;76:1553-60.

13. Kostner KM, Kostner GM. Lipoprotein(a): still an enigma? Curr Opin Lipidol. 2002; 13: 391-6.

14. Mohan V, Deepa R, Harnath SP et al. Lipoprotein(a) is an independent risk factor for coronary artery disease in NIDDM patients in south India. Diabetes Care 1998;21:1819-23.

15. Salehi R, Rahbani MN, Rashtchizadeh N. Lipoprotein(a), apo(a) phenotypes and dyslipidemia in acute coronary syndrome. Med J Islam Repub Iran 2001;14(4):139-143.

16. Neki AD, Durrington PN, Serum Lp(a) lipoprotein concentration and outcome of thrombolytic treatment for myocardial infarction. Br Heart J. 1994;71:316-321.

17. Ramirez LC,Arauz-Pacheco C,Lackner C, et al.Lipoprotein (a) levels in diabetes mellitus: relationship to metabolic control. Ann intern med 1992;117:42-7.

18. Abu-Lebdeh HS, Hodge DO, Nguyen TT. Predictors of macrovascular disease in patients with type 2 diabetes mellitus. Mayo Clin Proc. 2001; 76 (7): 707-12.

19. Klaya F, Durlach V, Bertin E, Monier F, Monboisse JC, Gillery P. Evaluation of serum glycated lipoprotein(a) levels in non insulindependent diabetic patients. Clin Biochem. 1997; 30 (3): 227-30.

20. Wieringa G. Lipoiprotein(a): what's in a measure. Ann Clin Biochem. 2000; 37: 57180. 